\title{
Mountain day: isomorphism of mountaineering and science
}

\author{
Tetsuro Matsuzawa ${ }^{1,2,3}$
}

Published online: 12 September 2016

(C) Japan Monkey Centre and Springer Japan 2016

A new national holiday was created in Japan this year: Mountain Day. It must be rare, if not unique, to have such a national holiday. Japan already has a 'Marine Day' in July. From now on, we will celebrate Mountain Day every August 11th. Japan is surrounded by sea, and consists of a series of islands, mountainous and covered in forest. We are very proud to have such a distinct national holiday, linked to Nature.

I am the current president of the Academic Alpine Club of Kyoto (AACK), founded in 1931 (I am the 14th President). Members of the AACK pioneered attempts at first ascents in the Himalayas, particularly in the 50s and 60s. The founding members of the AACK were Kinji Imanishi (1902-1992), Eizabro Nishibori (1903-1989) and colleagues, at Kyoto University. Kinji Imanishi was also the founding editor of this journal, Primates. The aim of the AACK was to launch climbing expeditions to go to the Himalayas. Please take a look at the history of this society on the official website: http://www.aack.info/.

As the main representative of academia in relation to mountaineering, I took the role of deputy president of the nationwide assembly to create the 16th National holiday. The first Mountain Day ceremony was held in Kamikochi, Matsumoto, Nagano prefecture, August 11th 2016. Attending the ceremony were His Royal Highness, the Crown Prince Naruhito, the Crown Princess Masako, and their Princess, Aiko. The Japanese Royal family's love of

Tetsuro Matsuzawa

matsuzawa.tetsuro.8w@kyoto-u.ac.jp

Institute of Advanced Study, Kyoto University, Kyoto, Japan

2 Primate Research Institute, Kyoto University, Inuyama, Japan

3 Japan Monkey Centre, Inuyama, Japan mountaineering is well known. We enjoyed the beautiful landscape of Mt. Hodaka in the Japanese Alps. It was very cool weather that morning, $12{ }^{\circ} \mathrm{C}$.

Why was August 11th chosen as the date for Mountain Day? There is no explicitly stated reason. However, the

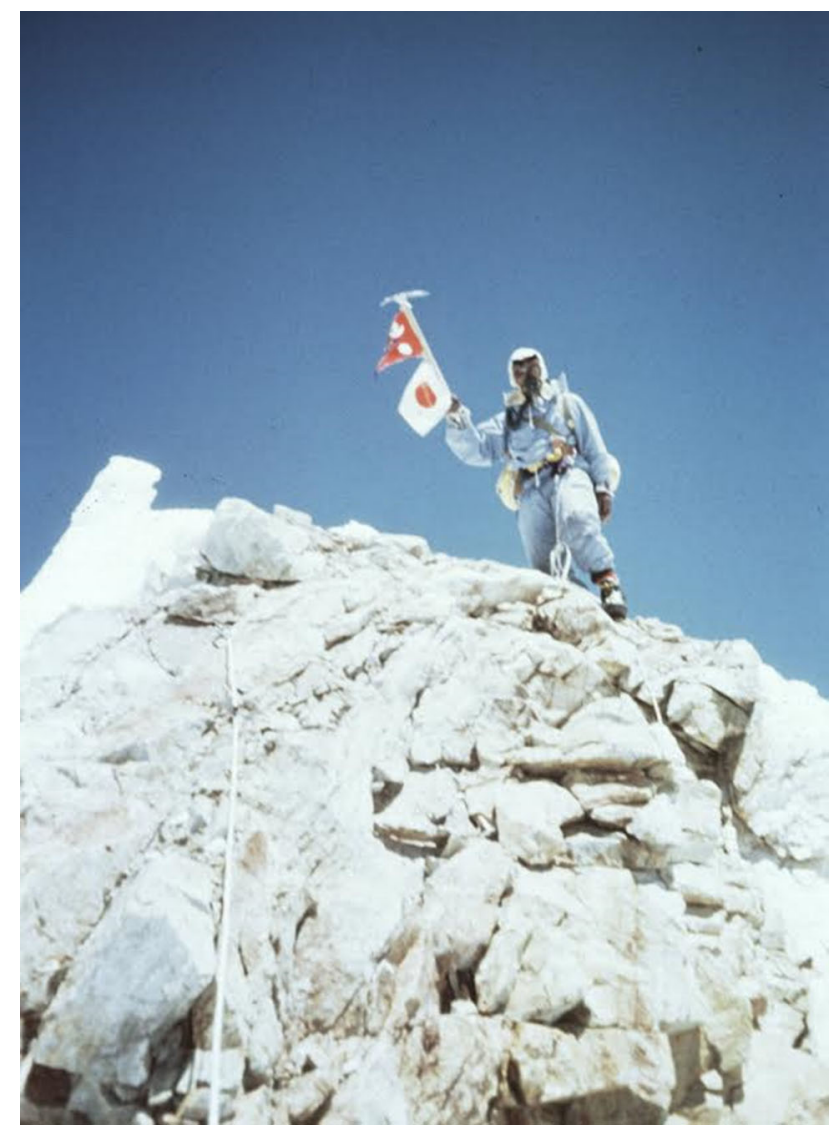

Fig. 1 Japanese mountaineer, Toshio Imanishi, on the summit of Manaslu, 1956 
date is in mid-August: matching the peak mountaineering season, in the summer vacation. Another possible reason is that there were previously no national holidays in either June or August (in Japan, there is already at least one national holiday in every other calendar month). June is the month of the inclement rainy season here in Japan, so mid-August was a preferable option for a national holiday.

If the Japanese public had been asked to suggest an appropriate date for Mountain Day, I am sure that many would have chosen May 9th. Why should that be? It was the day that a Japanese mountaineer reached the summit of Manaslu (8163 m), in Nepal. Toshio Imanishi (1914-1995) and his partner Gyaltsen Norbu Sherpa succeeded in the first ascent of Manaslu (Fig. 1). Incidentally, Toshio Imanishi was a Kyoto University graduate and a member of AACK, but was not related to Kinji Imanishi. This year, 2016 , is the 60th anniversary of that landmark ascent.

There are only 14 independent mountains above $8000 \mathrm{~m}$ in the Himalayas. Humans first reached the summit of peaks over $8000 \mathrm{~m}$ in 1950. A French expedition, led by Maurice Herzog, reached the top of Annapurna (8091 m). The summit of the highest mountain in the world, Everest (8848 m), was reached in 1953 by a British team. The world's second highest mountain, K2 (8611 m), was climbed in 1954 by an Italian expedition, while the third highest mountain, Kangchenjunga $(8586 \mathrm{~m})$, had been attempted by German teams and was finally climbed by a British team in 1955. Europeans and Americans attempted first ascents of peaks higher than $8000 \mathrm{~m}$ in the early 1950s. Japanese climbers also wanted to carry out first ascents of peaks over $8000 \mathrm{~m}$.

It was Kinji Imanishi and fellow AACK members who had the initial idea to climb Manaslu. Manaslu was an almost unknown peak at that time, not yet explored by Western mountaineers. Imanishi and Nishibori were of the same age and could be considered spiritual twins. Imanishi asked Nishibori, who spoke fluent English, to go to Nepal to secure a climbing permit from the government. This was near the end of December 1951. It must be noted that, at that time, Japan was officially called 'Occupied Japan'. The country was not yet independent, but still occupied by America and allies. In this context, you can easily imagine how difficult it was for a young Kyoto University professor to go to Nepal, a country only just open to the outside world, right after the Second World War.

Nishibori succeeded in getting governmental permission in May 1952. Imanishi and Nishibori then decided to transfer the permission to the Japanese Alpine Club (JAC) to form a national team from Japan, rather than being from Kyoto University only. In October 1952, Imanishi led a small party of JAC members to Manaslu. The party walked around this unknown mountain clockwise, from the south, to find a possible route to the summit. Imanishi's reconnaissance team found that the north east glacier presented the easiest climbing route. JAC sent two expeditions, in 1953 and 1955, respectively, but these failed to reach the summit. The third such expedition team, in 1956, finally succeeded in setting foot on this pristine peak.

Why were Imanishi and his comrades motivated so strongly to become pioneers of mountaineering? History suggests that it was the atmosphere of freedom in the 1920s, and the silent invasion of the pioneering spirit from the West to the minds of young people in the Far East (Matsuzawa and McGrew 2008). It may also be due, in part, to the influence of Albert Einstein (1879-1955). The news that he had won the Nobel Prize for Physics reached him as he was on his way to Japan for the first time. Einstein and his wife arrived in Japan on November 17th 1922 and stayed for a total of 43 days. Touring Japan, he gave talks explaining how he had come up with the general theory of relativity. When Einstein came to Kyoto to give a plenary talk at the Kyoto Imperial University, Nishibori was given the role of personal tour guide for Einstein's 3-day stay (Fig. 2).

It is easy to imagine how this youth was influenced immensely by the charismatic Nobel prize-winner. No doubt, this excitement was shared by Imanishi, Nishibori's closest friend. Let us imagine an autumn day in 1922 in Kyoto. Imanishi, Nishibori and their young friends, are spending their days within a very small area; less than one square kilometer. They were in their late teens, preparing to tackle the world outside Japan. Inspired by Einstein's pioneering work, their desire to understand the world around them increased. The wind from the West may have

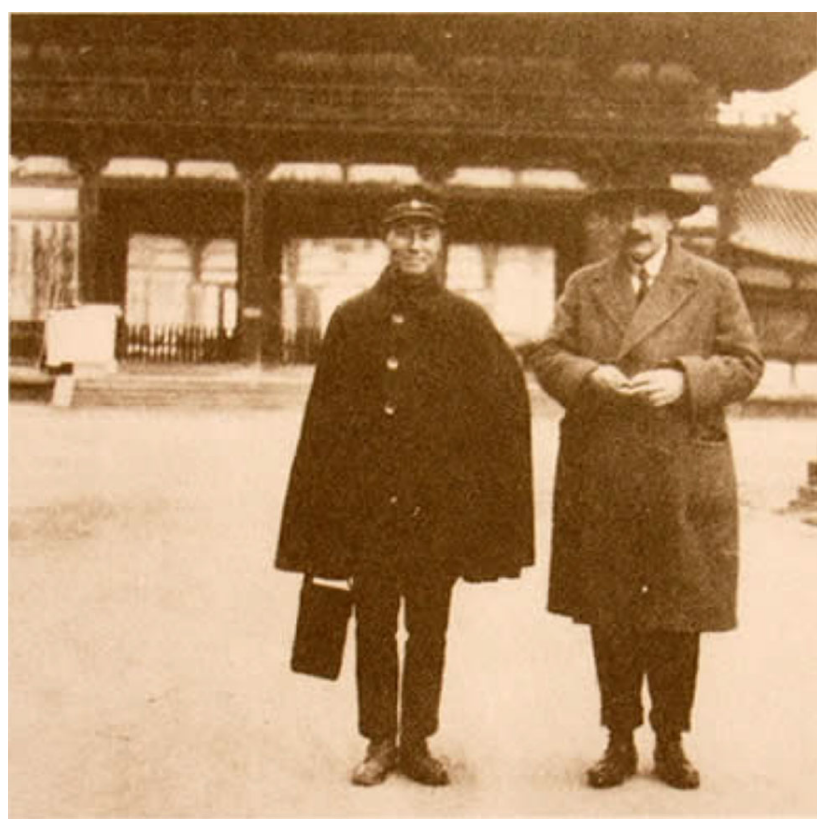

Fig. 2 Eizabro Nishibori (left) and Albert Einstein (right) in Kyoto in 1922. (Photo courtesy of the Nishibori Memorial Explorer Museum) 
triggered such young minds to strive to do pioneering work of their own.

Nishibori got married to Imanishi's sister, making them brothers-in-law. After the Manaslu attempt, Nishibori shifted to pioneering work in the Antarctic. He was the leader of the first Japanese over-wintering party in the Antarctic, in 1957. He later became a multi-talented scholar, inventing innovative electric components, creating the first nuclear-powered ship in Japan, and was a frontrunner in quality-control research. Imanishi, after the Manaslu reconnaissance, also changed focus in 1955, to the investigation of the unexplored range of the Karakorum Himalayas which spans a vast distance. He traversed all three of the major glaciers located there. Next, in 1958, Imanishi and his student Jun'ichiro Itani made the journey to Africa for the first time (Fig. 3). They wanted to start fieldwork on wild gorillas and, once there, shifted their sights to wild chimpanzees. This was 2 years before Jane Goodall started the long-running wild chimpanzee fieldsite at Gombe.

In 1973, AACK sent the first expedition to Yalung Kang $(8505 \mathrm{~m})$. It is the Western peak of the Kanchenjunga massif and was the highest untrodden peak at that time. Nishibori was the expedition leader at the age of 70 , and the oldest member. (Figure 4). At 22 years old, I was the youngest expedition member. It happened that I was with him at the base camp, located at an altitude of $5500 \mathrm{~m}$. Nishibori was industriously occupied even during the night, placing small glass plates here and there on rocks. I asked him what he was doing in the middle of the night. According to his explanation, Nishibori was trying to capture fine particles of matter in space, called cosmic dust.

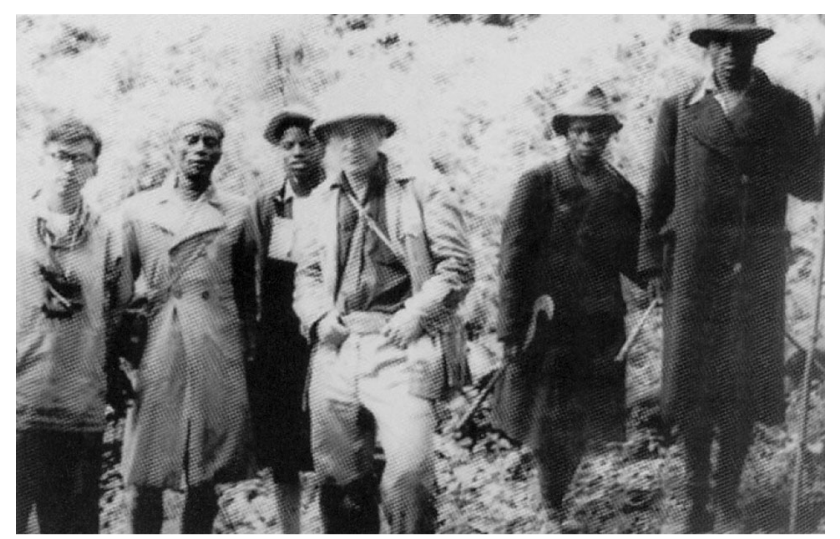

Fig. 3 Kinji Imanishi (center) and Jun'ichiro Itani (left), in search of wild gorillas in Uganda, March 6th 1958. (Photo from the Itani Jun'ichiro Archives at the Primate Research Institute, Kyoto University)

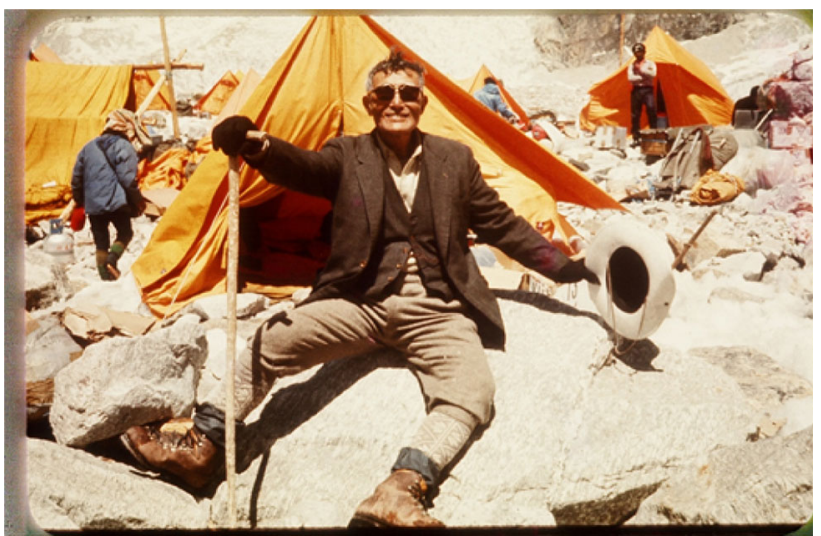

Fig. 4 Eizabro Nishibori at the Yalung Kang Base Camp (5500 m) in 1973 (Photo credit: AACK)

Cosmic dust is pronounced Uchu-jin in Japanese. Uchu-jin pronounced the same way has two meanings, one of which is 'alien'. He was capturing aliens?! I thought for sure that he must have gone crazy as a result of the low oxygen levels at very high altitudes, until I understood what he meant. Nishibori at the age of 70 was a thoroughly charming old man who maintained his curiosity towards nature. Those were very precious days for me, spent in the company of Nishibori.

After the 1973 Kangchenjunga West expedition, I got a job at the Primate Research Institute of Kyoto University and started the Ai Project. However, in a parallel effort, I continued to keep my mind directed toward high mountains. I attempted to summit Kangchenjunga once again in 1984, ascending to the considerable altitude of $8350 \mathrm{~m}$ without oxygen (Fig. 5). My third expedition was to Muztagh Ata $(7456 \mathrm{~m})$ in 1989. I reached the summit on skis and then skied right to the base of the mountain from the very top! My fourth and final mountaineering venture was Shishapangma $(8027 \mathrm{~m})$ in Tibet, in 1990 . Upon reaching the summit of over $8000 \mathrm{~m}$, I came to the realization that the summit of a mountain is a very special place. Only from the summit can you get such a superb $360^{\circ}$ view, not available at any location below this point of elevation.

Through my parallel efforts in mountaineering and primatology over the course of decades, I think that I came to apply a mountaineer's perspective to the practice of science, without being consciously aware of doing so (Matsuzawa 2009). In my opinion, the crux of the matter is to carry out pioneering endeavors. You have to go to places where no one has ever reached before. You have to think of things that no one has ever thought before. You have to find the route that no one has ever tried before. Pioneering work is necessary for any kind of innovation or invention. 


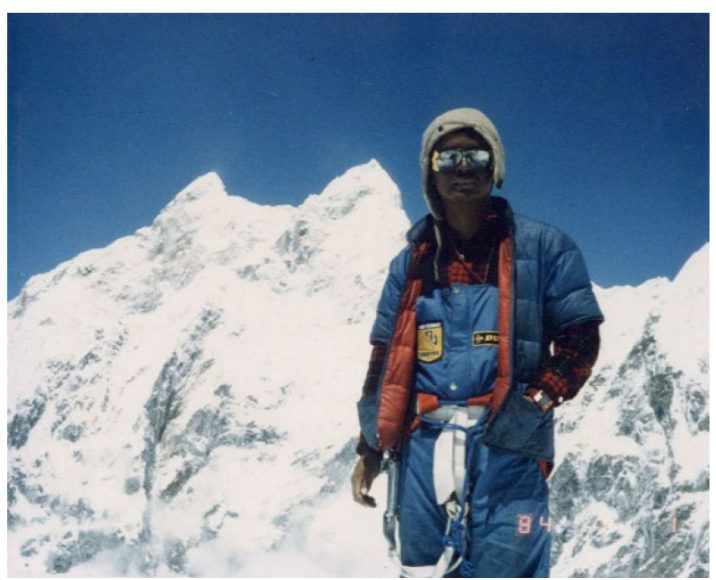

Fig. 5 Tetsuro Matsuzawa on Kangchenjunga in 1984. In the background is Kumbhakarna (Jannu), 7710 m, one of the hardest peaks in the world in terms of technical difficulty
To reach the summit, you must first do a whole variety of tasks, such as checking existing records, maps, photos, etc. You have to train yourself in order to hone your techniques and accumulate experience. You need to obtain physical strength and also mental strength. To that end, you should make the effort to do things "step by step". The phrase "step by step" is synonymous with "day by day", "one by one". It must also be "side by side", that means: in collaboration with your trusted colleagues.

\section{References}

Matsuzawa T (2009) Q\&A Tetsuro Matsuzawa. Curr Biol 19:R1-R2 Matsuzawa T, McGrew W (2008) Kinji Imanishi and 60 years of Japanese primatology. Curr Biol 18:R587-R591 